\title{
MOLECULAR DOCKING, DESIGN, SYNTHESIS AND BIOLOGICAL EVALUATION OF NOVEL BENZODIOXOLE DERIVATIVES ON VARIOUS BIOLOGICAL TARGETS
}

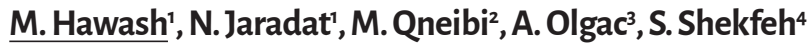 \\ and M. Abualhasan' \\ ${ }^{1}$ Department of Pharmacy, Faculty of Medicine and Health Sciences, \\ An- Najah National University, Palestine. \\ ${ }^{2}$ Department of Biomedical Sciences, Faculty of Medicine and Health Sciences, \\ An-Najah National University, Nablus, Palestine. \\ ${ }^{3}$ Department of Pharmaceutical Chemistry, Faculty of Pharmacy, \\ Gazi University, Yenimahalle, Ankara 06330, Turkey. \\ ${ }^{4}$ MTS, Medicinal Chemistry, Wolframstr. 3, 86161 Augsburg, Germany.
}

DOI: 10.19163/MedChemRussia2021-2021-74

E-mail: Mohawash@najah.edu

18 Novel Benzodioxole derivatives (three different groups; benzodiazepine, aryl acetate, and acetic acid) were synthesized in order to evaluate their biological activities on various targets. The synthesized compounds were identified using FTIR, HRMS, 1H-NMR, and 13C-NMR techniques. The analogues were evaluated on AMPA receptor, COX, lipase, $\alpha$-amylase, DPPH enzymes, as well as on different cancer cell lines. The group with benzodiazepine structures were active on AMPA receptors [1]. Aryl acetate derivatives showed potent activity on COX2 enzymes, while two compounds of acetic acid group were the most selective agents on COX2 over COX1 enzyme [2]. Three compounds have potent activity against $\alpha$-amylase with IC50 below the value of Acarbose, and one compound showed potent cytotoxicity against cancer cell line MCF7. The compounds showed very week activity on the lipase. Molecular docking studies were used to identify the Receptor-Antagonist interactions between Benzodiazpine compounds and AMPA receptor, and between aryl acetic acid group and $\alpha$-amylase enzyme.

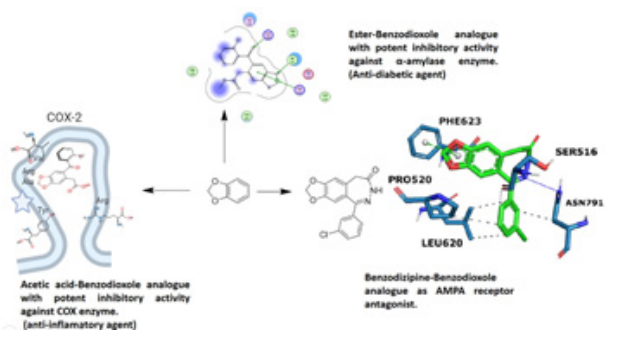
A good correlation was obtained between the theoretical predictions of bioavailability using Molinspiration calculation, Lipinski's rule and experimental verification. The work provides possible drug candidates on AMPA receptor for neurological diseases (benzodiazepine group), promising group of compounds having a

benzodioxole moiety against COX enzyme as novel Non-steroidal anti-inflammatory agents, as well as promising compounds against diabetes disease (see the figure).

\section{References}

1. Qneibi M, Jaradat N, Hawash M, Olgac A, Emwas N. ACS Omega. 2020; 5(7), 3588-95.

2. Hawash M, Jaradat N, Hameedi S, Mousa A. BMC Chem. 2020; 14(1), 1-9. 